\title{
Materiais pictóricos da cerâmica Guarani do alto Uruguai a partir de medidas de fluorescência de raios $\mathrm{X}$
}

\author{
Mirian Carbonera * \\ Carlos R. Appoloni ** \\ Gustavo H. dos Santos ***
}

\begin{abstract}
CARBONERA, M.; APPOLONI, C.R.; SANTOS, G.H. Materiais pictóricos da cerâmica
Guarani do alto Uruguai a partir de medidas de fluorescência de raios X. R. Museu Arq. Etn., 28: 133-144, 2017.
\end{abstract}

Resumo: Os Guarani pré-coloniais estavam distribuídos por grandes áreas da América do Sul, especialmente em regiões da Bacia do Rio da Prata e zonas litorâneas do Sul do Brasil. A grande característica em termos de cultura material é sua produção cerâmica, com destaque para os vasilhames pintados tanto na superfície externa como na interna. Apresentamos, a partir de medidas de fluorescência de raios $\mathrm{X}$, a análise dos dados de proveniência dos pigmentos utilizados na produção das tintas aplicadas no acabamento de cerâmicas da unidade Guarani de três sítios arqueológicos localizados na Volta do Uvá, alto rio Uruguai. Esta análise indicou que os pigmentos vermelho e branco provêm de materiais inorgânicos derivados de minerais terrosos.

Palavras-chave: Unidade Guarani; Cerâmica; Fluorescência de raios X; Alto rio Uruguai.

\section{Introdução}

Dor meio de medidas de fluorescência

de raios X, objetivamos trazer novos dados sobre a proveniência dos pigmentos utilizados na produção das tintas aplicadas nos acabamentos com pintura em cerâmicas Guarani. As amostras analisadas foram coletadas em sítios da Volta do Uvá (Fig. 1).

* Docente do Curso de Pós-graduação Stricto Sensu em Ciências Ambientais e Coordenadora do Centro de Memória do Oeste de Santa Catarina, ambos da Universidade Comunitária da Região de Chapecó.<mirianc@unochapeco.edu.br>

** Docente do Departamento de Física, Graduação e Programa de Mestrado e Doutorado, Universidade Estadual de Londrina.<appoloni@uel.br>

*** Graduado em Física, Universidade Estadual de Londrina. <gustavo.gustavoh@gmail.com>
Na região do Alto Rio Uruguai foram registradas centenas de sítios arqueológicos Guarani (Caldarelli 2010; De Masi 2012; Goulart 1995, 1997; Piazza 1969, 1971; Rohr 1966; Schmitz 1957). Um elemento característico dessa unidade é a pintura na cerâmica, comum tanto na face interna como na externa, em geral com traços vermelhos sobre o engobo branco, mas também em alguns casos ocorre o contrário, as peças apresentam engobo vermelho com traços brancos. Estudos de coleções de cerâmica pintada de sítios do alto Uruguai foram realizados por Oliveira $(2009,2011)$ e Mohr (2015). No tocante a origem dos pigmentos, no trabalho de Ali et al. (2017) foram analisados fragmentos de cerâmica pintada Tupiguarani por meio do 
Materiais pictóricos da cerâmica Guarani do alto Uruguai a partir de medidas de fluorescência de raios X

R. Museu Arq. Etn., 28: 133-144, 2017.

método físico-químico MEB-EDX, comparando amostras dos sítios Caxambu do Sul, localizado no oeste catarinense e, Corpus, localizado na província de Misiones, na Argentina.

Pesquisas de proveniência indicam que as cores vermelha e amarela derivam de minerais como a hematita $\left(\mathrm{Fe}_{2} \mathrm{O}_{3}\right)$ e a goethita $(\mathrm{FeO}(\mathrm{OH}))(\mathrm{KERN}$ et al. 2013: 104). Já as variações de tons nas pinturas estariam relacionadas às diferentes concentrações de óxido de ferro (Shepard 1956; Rye 1981). Pesquisas arqueométricas realizadas na pintura de cerâmica Tupiguarani no Brasil apontam óxidos de ferro como os minerais responsáveis pela pigmentação (Appoloni, 2015; Appoloni et al. 1997).

No trabalho de Ali et al. (2017) são indicadas variações nos pigmentos, ao comparar amostras cerâmicas Tupiguarani dos sítios Corpus e Caxambu do Sul. Quanto a cor vermelha, as amostras de ambos os sítios apontam para o emprego do óxido de ferro, embora os valores sejam diferentes (Ali et al. 2017). Segundo as autoras, a cor preta no sítio Corpus apresenta mais carbono e menos manganês, ao passo que, no sítio Caxambu do Sul a situação foi inversa, para o qual se propôs o uso da pirolusita. Já para a cor branca, as autoras apontam no sítio Corpus níveis levemente elevados de fósforo, mas não tão elevados de cálcio, que poderia ser vinculado a hidroxiapatita $\left(\mathrm{Ca}_{5}\left(\mathrm{PO}_{4}\right)_{3}(\mathrm{OH})\right)$ componente presente nos ossos. Já a cor branca presente nos pigmentos do sítio Caxambu do Sul aponta para o uso de argila branca, como a caolinita $\left(\mathrm{Al}_{2} \mathrm{Si}_{2} \mathrm{O}_{5}(\mathrm{OH})_{4}\right)$ (Ali et al. 2017).

Análises arqueométricas de cerâmicas da região amazônica apontam, além dos minerais de óxidos de ferro, outras fontes possivelmente orgânicas (Kern et al. 2013: 104). No entanto, Souza, Jácome \& Rocha (2010) indicam que os materiais pictóricos podem ser orgânicos e inorgânicos, embora os orgânicos, por serem mais suscetíveis à degradação, não se preservariam por muitos séculos, ao contrário dos pigmentos à base de minerais, que são mais estáveis e se conservariam por muito mais tempo. Ainda segundo os autores, nas análises realizadas em cerâmicas Tupiguarani do estado de Minas Gerais, constatou-se que a tinta branca seria proveniente do caulim, formado à base de silicatos hidratados de alumínio; já os tons ocre, amarelo e vermelho derivam do ferro, mostrando que as bases dos pigmentos são minerais (Souza, Jácome \& Rocha, 2010).

\section{Materiais e métodos}

Neste artigo serão analisados somente dados relativos a três amostras cerâmicas Guarani, provenientes de dois sítios multicomponenciais a céu aberto, registrados na localidade de Linha Borboleta Baixa, no município de Itá (SC) (Fig. 1). Essa região também é conhecida como Volta do Uvá, devido a extensa curva do rio Uruguai onde desemboca o afluente rio Uvá.

O sítio Armandio Vortmann (011) está localizado a $27^{\circ} 15^{\prime} 24.78^{\prime \prime}$ e e $52^{\circ} 22^{\prime} 49.85^{\prime \prime} \mathrm{O}$, na propriedade de Armandio Vortmann, Itá (SC). Situado no segundo terraço, em área plana na margem direita do rio Uruguai e próximo à foz do rio Uvá com o Uruguai (Goulart 1988: 27; Carbonera 2014). O sítio apresentou duas ocupações, a mais antiga com grupos Itararé-Taquara e a mais recente, Guarani, datada por termoluminescência ${ }^{1}$ em 358 AP (Carbonera 2014).

O sítio Otto Aigner 1 (013) está localizado $27^{\circ} 14^{\prime} 59.98^{\prime \prime}$ S e $52^{\circ} 23^{\prime} 36.03^{\prime \prime} \mathrm{O}$, na propriedade de Otto Aigner, Itá (SC). Situado a aproximadamente 25 metros do rio Uruguai e assentado na feição geomorfológica de segundo terraço (Goulart 1987: 63; Carbonera 2014). O sítio apresentou ocupação précerâmica do Holoceno antigo e outras duas com grupos do Holoceno tardio, primeiro os Itararé-Taquara e a mais recente, Guarani, datada por termoluminescência em 335 AP (Carbonera 2014).

A cerâmica Guarani dos dois sítios analisados totalizou 839 fragmentos, como observado na Tabela 1.

1 As datas mencionadas neste artigo foram processadas no laboratório da Universidade Federal de São Paulo (Unifesp - Campus Baixada Santista). 
Mirian Carbonera

Carlos R. Appoloni

Gustavo H. dos Santos
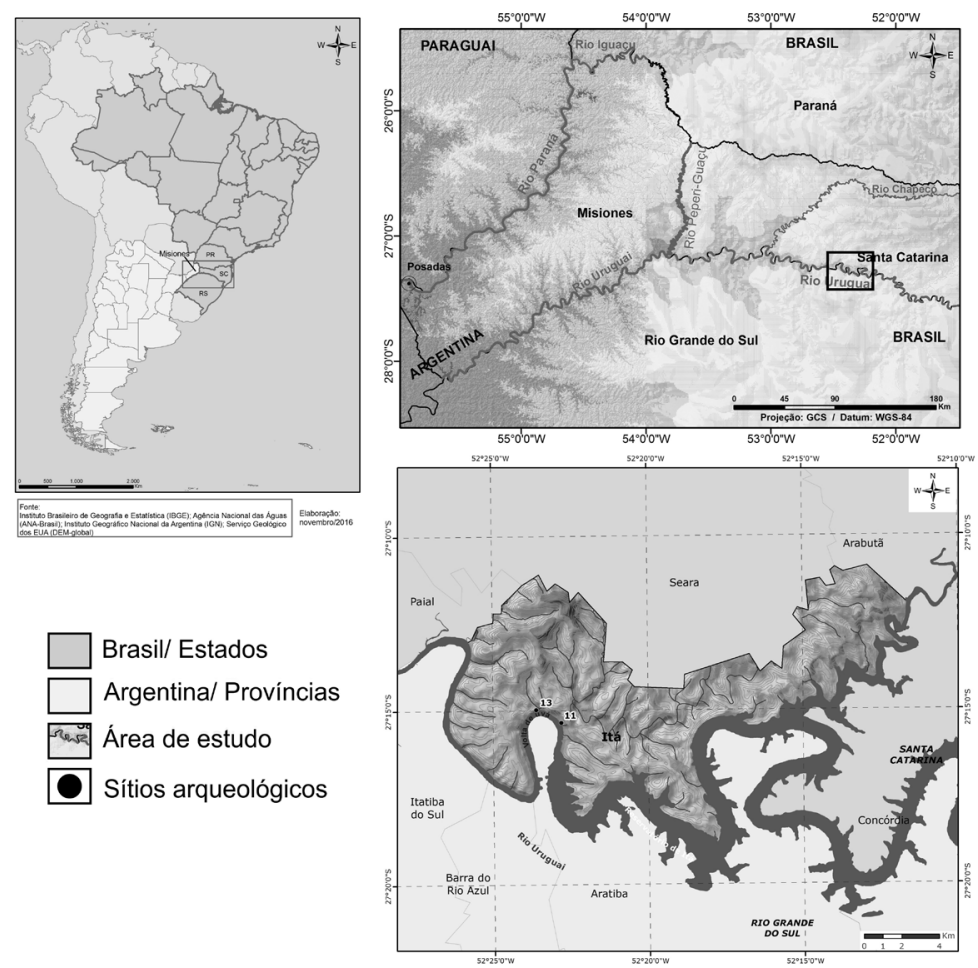

Fig. 1. Localização dos sítios Armandio Vortmann (011) e Otto Aigner 1 (013).

Fonte: Elaborado pelos autores com base em Carbonera, 2014.

\begin{tabular}{lcccccc}
\hline \multicolumn{1}{c}{ Sítio } & Simples & Pintado & Corrugado & Ungulado & Outros $^{*}$ & Total \\
\hline \multirow{2}{*}{ Armandio Vortmann (011) } & 314 & 36 & 86 & 35 & 49 & 520 \\
& $60,38 \%$ & $6,92 \%$ & $16,53 \%$ & $6,75 \%$ & $9,42 \%$ & $100 \%$ \\
Otto Aigner 1 (013) & 231 & 21 & 53 & 5 & 9 & 319 \\
& $72,41 \%$ & $6,58 \%$ & $16,61 \%$ & $1,58 \%$ & $2,82 \%$ & $100 \%$ \\
Total & 545 & 57 & 139 & 40 & 58 & 839 \\
& $64,95 \%$ & $6,79 \%$ & $16,56 \%$ & $4,76 \%$ & $6,94 \%$ & $100 \%$ \\
\hline
\end{tabular}

* Como "outros" foram reunidos acabamentos com baixa frequência, como escovado, espatulado, imbricado e as composições como corrugadoespatulado e corrugado-ungulado.

Tabela 1. Tratamento de superfície face externa.

Fonte: Elaborada pelos autores com base em Carbonera (2014).

No conjunto analisado, a pintura não se preservou bem. Embora os fragmentos com pintura na face externa somem $6,79 \%$, para grande parte deles se nota apenas a camada de engobo branco. Quanto à face interna, a pintura foi identificada em 40 fragmentos do sítio Otto Aigner 1 (013) e em 11 fragmentos do sítio Armandio Vortmann (011) (Fig. 2).
A pintura interna mal preservada possibilitou apenas visualizar o engobo branco, em poucos fragmentos perceberam-se linhas vermelhas - por isso, para medidas de fluorescência de raios $\mathrm{X}$ foram selecionados apenas três fragmentos de cerâmica em melhor estado de conservação, todos com pintura na face externa. Duas peças 
pertencem ao sítio Armando Vortmann (011), identificadas como "SCXI 766" e "SCXI 781", e um fragmento cerâmico pertencente ao sítio Otto Aigner 1 (013), identificado como "SCXIII 54".

Diferentes combinações metodológicas podem ser empregadas visando responder a distintas questões relativas às cerâmicas arqueológicas (Appoloni 2015). Neste trabalho, optamos pela fluorescência de raios $\mathrm{X}$, as medidas foram realizadas na pasta, na face interna e externa dos fragmentos, com o objetivo de comparar os espectros de forma qualiquantitativa, ou seja, além de identificados os elementos presentes em cada medida, também foram calculadas as áreas líquidas das linhas de fluorescência correspondentes a cada elemento.
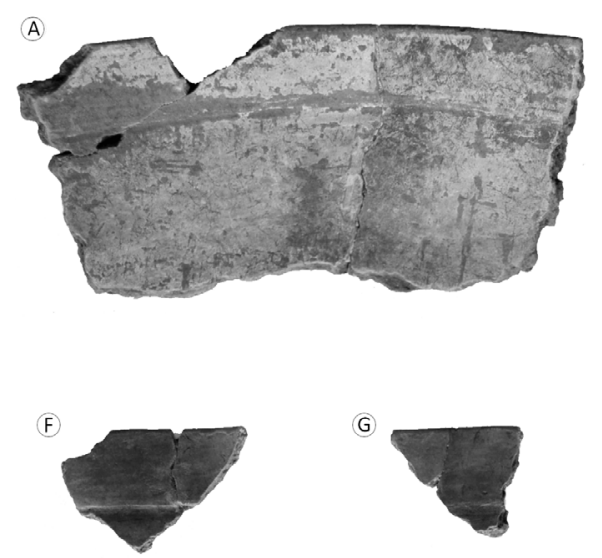

(G)

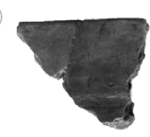

As medidas foram processadas no Laboratório de Física Nuclear Aplicada, do Departamento de Física da Universidade Estadual de Londrina. O sistema de fluorescência de raios X portátil (PXRF) é constituído de um minitubo de raios $\mathrm{X}$ de $4 \mathrm{~W}$ com um alvo e filtro de Ag (modelo FTC 100 Moxtek Inc.), um detector de Si-Drift com resolução de $139 \mathrm{eV}$ para a linha de 5,9 keV (Modelo SDD X123 Amptek) e eletrônica padrão. $\mathrm{O}$ detector e o minitubo de raios $\mathrm{X}$ são posicionados num suporte com graus de liberdade de translação e rotação em relação à amostra. Foi empregado um colimador de $\mathrm{Ag}$ de $3 \mathrm{~mm}$ de diâmetro na entrada do detector e utilizado o aplicativo PMCA Amptek para a aquisição dos dados. Os espectros foram analisados e quantificados com o aplicativo WINQXAS (AXIL).
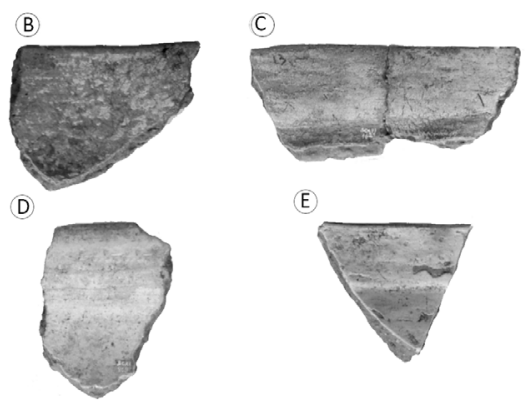

(E)

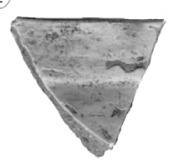

(H)

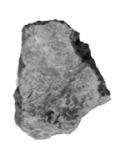

(1)

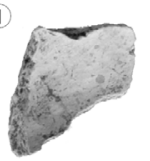

Fig. 2. Bordas de cerâmica Guarani com pintura interna, dos sítios Armandio Vortmann (b, c, d, h, i) e Otto Aigner (a, c, e, f, g).

Fonte: Ceom/Unochapecó 2016.

\section{Resultados}

A amostra "SCXIII 54" corresponde a fragmento de cerâmica pintada na face externa, a queima apresenta-se oxidada de forma incompleta. Por ser a parte superior do bojo, permite inferir que se trata de fragmento da classe tipológica cambuchí caaguâba. A pasta apresentou como inclusões quartzo, minerais opacos, chamote e calcedônia.

Foram realizadas três medidas de fluorescência de raios $\mathrm{X}$ na superfície interna, nomeadas como A1, A2 e A3 (Fig. 3); três medidas na face externa sobre a região com pintura branca, nomeadas B1, B2 e B3; e por fim as medidas da pasta cerâmica, denominadas 
P1, P2 e P3 (Fig. 3). Nessa amostra foi possível identificar os elementos relacionados na Tabela 2. A Fig. 4 apresenta a comparação entre dois dos espectros de fluorescência de raios
X medidos para a amostra "SCXIII 54", um para a pasta cerâmica e outro para a região do engobo branco. As diferenças serão discutidas detalhadamente a seguir.

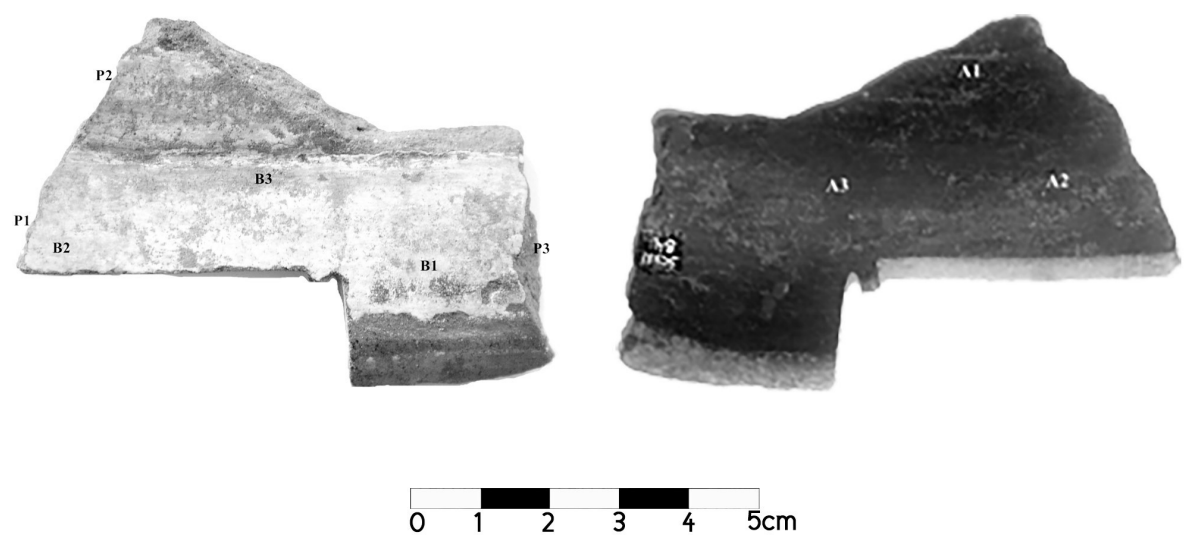

Fig. 3. Sítio Otto Aigner 1 (013), fragmento SCXIII 54, com a localização dos pontos em que foram realizadas as medidas.

Fonte: Ceom/Unochapecó, 2016.

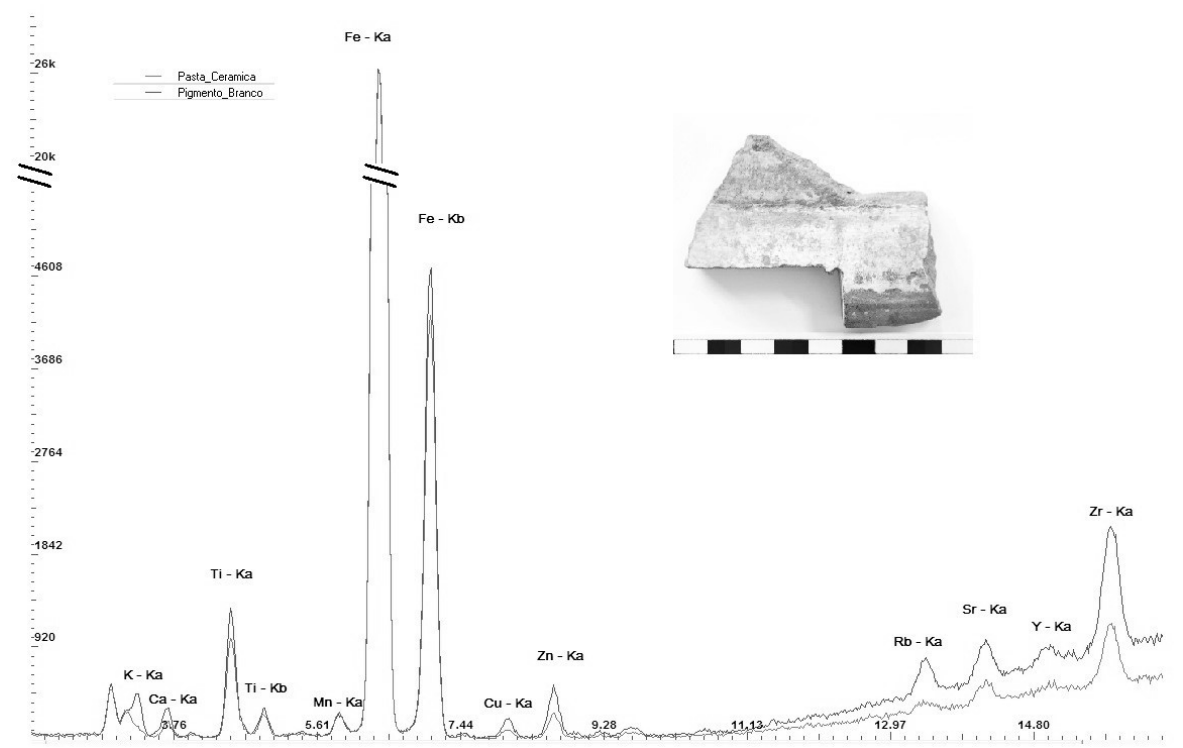

Fig. 4. Fragmento "SCXIII 54", comparação entre espectros de fluorescência de raios X de uma das medidas da pasta cerâmica e do engobo branco. Escalas: Contagens versus energia dos raios X (em KeV).

Fonte: Elaborada pelos autores, 2016. 
Materiais pictóricos da cerâmica Guarani do alto Uruguai a partir de medidas de fluorescência de raios X R. Museu Arq. Etn., 28: 133-144, 2017.

\begin{tabular}{ccccccccccc}
\hline Elemento & $\mathrm{B} 1$ & $\mathrm{~B} 2$ & $\mathrm{~B} 3$ & $\mathrm{~A} 1$ & $\mathrm{~A} 2$ & $\mathrm{~A} 3$ & $\mathrm{P} 1$ & $\mathrm{P} 2$ & P3 & Media P \\
\hline $\mathrm{K}$ & 2814 & 1627 & 1574 & 845 & 735 & 758 & 476 & 571 & 403 & 483 \\
$\mathrm{Ca}$ & 1409 & 1363 & 647 & 1900 & 1381 & 1697 & 709 & 847 & 249 & 602 \\
$\mathrm{Ti}$ & 10237 & 14801 & 6503 & 16496 & 13352 & 15487 & 8207 & 5793 & 3155 & 5718 \\
$\mathrm{Cr}$ & 407 & 411 & 213 & 361 & 328 & 286 & 251 & 153 & 56 & 153 \\
$\mathrm{Mn}$ & 1972 & 1843 & 781 & 2266 & 2068 & 2122 & 2214 & 1651 & 1238 & 1701 \\
$\mathrm{Fe}$ & 243329 & 351039 & 160601 & 349962 & 311678 & 322788 & 237745 & 159353 & 84873 & 160657 \\
$\mathrm{Ni}$ & 350 & 301 & 188 & 256 & 231 & 226 & 227 & 204 & 135 & 189 \\
$\mathrm{Cu}$ & 1753 & 1617 & 1216 & 1540 & 1203 & 1375 & 776 & 644 & 366 & 595 \\
$\mathrm{Zn}$ & 4561 & 3010 & 2382 & 2665 & 2443 & 2497 & 2268 & 1533 & 738 & 1513 \\
$\mathrm{Ga}$ & 234 & 161 & 123 & 176 & 109 & 125 & 77 & 59 & 0 & 45 \\
$\mathrm{Rb}$ & 4984 & 3271 & 2594 & 2509 & 2381 & 2572 & 1435 & 1285 & 743 & 1154 \\
$\mathrm{Sr}$ & 5140 & 4268 & 2941 & 3548 & 3433 & 3646 & 2629 & 2182 & 1008 & 1940 \\
$\mathrm{Y}$ & 960 & 515 & 339 & 326 & 302 & 509 & 303 & 307 & 0 & 203 \\
$\mathrm{Zr}$ & 15317 & 12366 & 8360 & 10374 & 10063 & 12632 & 6790 & 4799 & 2141 & 4576 \\
\hline
\end{tabular}

Tabela 2. Áreas líquidas dos elementos encontrados em cada medida da amostra "SCXIII 54", com destaque para os elementos Fe, Ti e Zr.

Fonte: Elaborada pelos autores, 2016.

\begin{tabular}{cccc}
\hline Elemento & B1 / MP & B2 / MP & B3 / MP \\
\hline $\mathrm{K}$ & 5,82 & 3,37 & 3,26 \\
$\mathrm{Ca}$ & 2,34 & 2,27 & 1,08 \\
$\mathrm{Ti}$ & 1,79 & 2,59 & 1,14 \\
$\mathrm{Cr}$ & 2,65 & 2,68 & 1,39 \\
$\mathrm{Mn}$ & 1,16 & 1,08 & 0,46 \\
$\mathrm{Fe}$ & 1,51 & 2,19 & 1,00 \\
$\mathrm{Ni}$ & 1,86 & 1,60 & 1,00 \\
$\mathrm{Cu}$ & 2,94 & 2,72 & 2,04 \\
$\mathrm{Zn}$ & 3,01 & 1,99 & 1,57 \\
$\mathrm{Ga}$ & 5,16 & 3,55 & 2,71 \\
$\mathrm{Rb}$ & 4,32 & 2,83 & 2,25 \\
$\mathrm{Sr}$ & 2,65 & 2,20 & 1,52 \\
$\mathrm{Y}$ & 4,72 & 2,53 & 1,67 \\
$\mathrm{Zr}$ & 3,35 & 2,70 & 1,83 \\
\hline
\end{tabular}

Tabela 3. Razões entre as áreas líquidas da região com decoração e a média da pasta cerâmica da amostra "SCXIII 54".

Fonte: Elaborada pelos autores, 2016.

A Tabela 2 apresenta os resultados das medidas para o fragmento "SCXIII 54"; a última coluna mostra a média aritmética simples das três medidas feitas sobre a pasta cerâmica. Fazendo a razão das áreas líquidas do ponto com pigmento pela média da pasta cerâmica (i.e. Ponto B1/Ponto Média P), os resultados são apresentados na Tabela 3.

As três medidas realizadas no fragmento "SCXIII 54" na face externa (B1, B2, B3) apresentam grande aumento dos elementos $\mathrm{K}$ (potássio), Ca (cálcio), Cr (cromo), Cu (cobre), Zn (zinco), Ga (gálio), Rb (rubídio), Sr (estrôncio), Y (ítrio) e Zr (zircônio). Como a região da medida B1 está sobre uma camada mais grossa de engobo que a da B2 e da B3, pode-se observar que a razão de alguns elementos em relação à pasta decresce de B1 para B3 - isto indica que um pigmento diferente foi utilizado, se fossem retirados do mesmo lugar, apresentariam as mesmas proporções entre os elementos. Outra possibilidade seria a adição intencional de outro material no engobo.

As medidas de B2 e B3 trazem, de fato, mais informações da pasta cerâmica que a medida de B1. Porém, quando comparadas com a média da pasta cerâmica, todas as medidas sobre o engobo 
branco apresentam quantidades maiores de alguns elementos para as três regiões. Caso esses elementos estivessem presentes na pasta cerâmica e não no engobo, a quantidade contabilizada pelo detector seria menor.

Considere-se como exemplo o elemento zinco. Quando medido na pasta cerâmica, apresentou média de 1.513 contagens. Se o zinco das medidas B1, B2 e B3 fosse proveniente da pasta cerâmica, as contagens teriam valor menor ou no máximo igual. Entretanto, como as contagens de zinco são maiores, mostram que o engobo contém o elemento e essa quantidade varia gradativamente de acordo com sua espessura.

A amostra "SCXI 781" corresponde à cerâmica pintada na face externa. Apresentou como queima oxidação incompleta e como inclusões na pasta: chamote, quartzo, calcedônia, minerais opacos, feldspato, turmalina e zircão. Características como a pintura externa e espessura entre $15 \mathrm{~mm}$ e $19 \mathrm{~mm}$ podem indicar que o fragmento pertença à classe tipológica dos cambuchi. Para esse fragmento foram realizadas na face externa quatro medidas de fluorescência de raios $\mathrm{X}$, duas sobre a pintura (B1 e B2) e duas sobre as áreas onde a tinta foi erodida (B3 e B4) (Fig. 5). Outras duas na face interna (A1, A2) e três da pasta (P1, P2, P3) (Fig. 5). Com as medidas realizadas, foram identificados os elementos descritos nas Tabelas 4 e 5 .

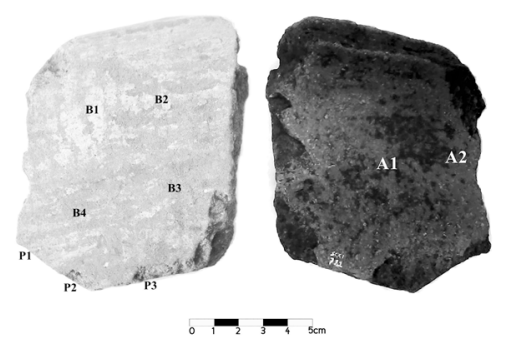

Fig. 5. Sítio Armando Vortmann (011), fragmento "SCXI 781", com a localização dos pontos em que foram realizadas as medidas.

Fonte: Ceom/Unochapecó, 2016.

\begin{tabular}{ccccccccccc}
\hline Elemento & $\mathrm{B} 1$ & $\mathrm{~B} 2$ & $\mathrm{~B} 3$ & $\mathrm{~B} 4$ & $\mathrm{~A} 1$ & $\mathrm{~A} 2$ & $\mathrm{P} 1$ & $\mathrm{P} 2$ & P3 & Media P \\
\hline $\mathrm{K}$ & 568 & 495 & 456 & 416 & 561 & 504 & 405 & 320 & 470 & 398 \\
$\mathrm{Ca}$ & 592 & 688 & 672 & 682 & 793 & 730 & 413 & 384 & 631 & 476 \\
$\mathrm{Ti}$ & 12258 & 11603 & 12992 & 11692 & 15516 & 14622 & 8010 & 8536 & 11824 & 9457 \\
$\mathrm{Cr}$ & 253 & 285 & 317 & 300 & 401 & 344 & 180 & 192 & 239 & 204 \\
$\mathrm{Mn}$ & 1259 & 1461 & 1180 & 2000 & 5055 & 5112 & 601 & 640 & 2971 & 1404 \\
$\mathrm{Fe}$ & 147334 & 155346 & 173859 & 169360 & 241335 & 232713 & 116144 & 121472 & 177413 & 138343 \\
$\mathrm{Ni}$ & 250 & 234 & 214 & 203 & 217 & 267 & 192 & 264 & 232 & 229 \\
$\mathrm{Cu}$ & 1117 & 1143 & 1213 & 1197 & 1404 & 1406 & 1111 & 1119 & 982 & 1071 \\
$\mathrm{Zn}$ & 2344 & 2230 & 2137 & 1969 & 2430 & 2803 & 1232 & 1264 & 1905 & 1467 \\
$\mathrm{Ga}$ & 231 & 265 & 215 & 198 & 331 & 277 & 273 & 296 & 252 & 274 \\
$\mathrm{As}$ & 203 & 212 & 208 & 178 & 228 & 167 & 138 & 129 & 163 & 143 \\
$\mathrm{Rb}$ & 2376 & 2337 & 2290 & 2225 & 2835 & 2747 & 1914 & 1960 & 1792 & 1889 \\
$\mathrm{Sr}$ & 2000 & 1938 & 2104 & 2224 & 2343 & 2191 & 2101 & 2247 & 1957 & 2102 \\
$\mathrm{Y}$ & 1514 & 1399 & 1378 & 1414 & 803 & 719 & 1268 & 1494 & 1329 & 1364 \\
$\mathrm{Zr}$ & 15801 & 14101 & 12677 & 11866 & 12513 & 13042 & 9056 & 9733 & 10938 & 9909 \\
\hline
\end{tabular}

Tabela 4. Áreas líquidas dos elementos encontrados em cada medida da amostra "SCXI 781".

Fonte: Elaborada pelos autores, 2016.

A pintura do fragmento "SCXI 781" apresentou os elementos $\mathrm{K}$ (potássio), Ca (cálcio), Ti (titânio), Cr (cromo), Fe (ferro), Cu (cobre),
Zn (zinco), As (arsênio), Rb (rubídio), Y (itrio) e Zr (zircônio); e na área com engobo branco nota-se maior presença de $\mathrm{K}, \mathrm{Zn}, \mathrm{As}$, Rb, Y e Zr. 


\begin{tabular}{ccccc}
\hline Elemento & $\begin{array}{c}\text { Razão } \\
\text { B1 }\end{array}$ & $\begin{array}{c}\text { Razão } \\
\text { B2 }\end{array}$ & $\begin{array}{c}\text { Razão } \\
\text { B3 }\end{array}$ & $\begin{array}{c}\text { Razão } \\
\text { B4 }\end{array}$ \\
\hline $\mathrm{K}$ & 1,43 & 1,24 & 1,14 & 1,04 \\
$\mathrm{Ca}$ & 1,24 & 1,45 & 1,41 & 1,43 \\
$\mathrm{Ti}$ & 1,30 & 1,23 & 1,37 & 1,24 \\
$\mathrm{Cr}$ & 1,24 & 1,40 & 1,56 & 1,47 \\
$\mathrm{Mn}$ & 0,90 & 1,04 & 0,84 & 1,42 \\
$\mathrm{Fe}$ & 1,06 & 1,12 & 1,26 & 1,22 \\
$\mathrm{Ni}$ & 1,09 & 1,02 & 0,93 & 0,89 \\
$\mathrm{Cu}$ & 1,04 & 1,07 & 1,13 & 1,12 \\
$\mathrm{Zn}$ & 1,60 & 1,52 & 1,46 & 1,34 \\
$\mathrm{Ga}$ & 0,84 & 0,97 & 0,79 & 0,72 \\
$\mathrm{As}$ & 1,42 & 1,48 & 1,45 & 1,24 \\
$\mathrm{Rb}$ & 1,26 & 1,24 & 1,21 & 1,18 \\
$\mathrm{Sr}$ & 0,95 & 0,92 & 1,00 & 1,06 \\
$\mathrm{Y}$ & 1,11 & 1,03 & 1,01 & 1,04 \\
$\mathrm{Zr}$ & 1,59 & 1,42 & 1,28 & 1,20 \\
\hline
\end{tabular}

Tabela 5. Razões entre as áreas líquidas da região com decoração e a média cerâmica da amostra "SCI 781". Fonte: Elaborada pelos autores, 2016.

A amostra "SCXI 766" é um fragmento de bojo com oxidação incompleta; dado o tamanho reduzido, não se pode inferir a que classe tipológica pertenceu. Dos três fragmentos analisados, é o que apresenta a pintura mais bem preservada, típica da tradição Guarani, na face externa se observa linhas vermelhas sobre branco, na face interna o fragmento está erodido em muitos pontos. Os pontos A1, A2 e A3 referem-se às medidas da face interna; na face externa os pontos B1 e B2 estão sobre a região de tinta branca, podendo atingir um pouco de vermelho ${ }^{2}$, e os pontos B3 e B4 sobre o vermelho com parte do branco (Fig. 6). Com as medidas, foram identificados os elementos descritos nas Tabelas 6 e 7.

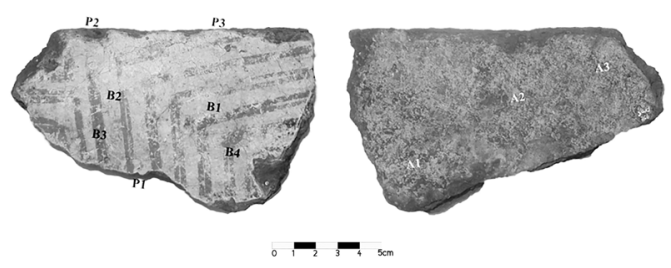

Fig. 6. Sítio Armando Vortmann (011), fragmento "SCXI 766", com a localização dos pontos em que foram realizadas as medidas.

Fonte: Ceom/Unochapecó, 2016.

\begin{tabular}{cccccccccccc}
\hline Elemento & $\begin{array}{c}\text { B1 } \\
\text { (branco) }\end{array}$ & $\begin{array}{c}\text { B2 } \\
\text { (branco) }\end{array}$ & $\begin{array}{c}\text { B3 } \\
\text { (verm.) }\end{array}$ & $\begin{array}{c}\text { B4 } \\
\text { (verm.) }\end{array}$ & A1 & A2 & A3 & P1 & P2 & P3 & $\begin{array}{c}\text { Media } \\
\text { P }\end{array}$ \\
\hline $\mathrm{K}$ & 1376 & 1245 & 1234 & 1227 & 558 & 635 & 1046 & 1205 & 1125 & 745 & 1025 \\
$\mathrm{Ca}$ & 1444 & 1632 & 2298 & 1494 & 440 & 761 & 1427 & 1273 & 1774 & 919 & 1322 \\
$\mathrm{Ti}$ & 14356 & 12521 & 13724 & 15202 & 5998 & 9143 & 16665 & 17785 & 20394 & 11224 & 16468 \\
$\mathrm{Cr}$ & 264 & 255 & 342 & 281 & 110 & 138 & 275 & 306 & 295 & 169 & 257 \\
$\mathrm{Mn}$ & 2966 & 2672 & 2363 & 2771 & 5816 & 6036 & 14864 & 4247 & 8645 & 5650 & 6181 \\
$\mathrm{Fe}$ & 189133 & 191739 & 219754 & 193198 & 66038 & 95987 & 169670 & 209692 & 243862 & 125711 & 193088 \\
$\mathrm{Ni}$ & 272 & 295 & 307 & 395 & 156 & 163 & 232 & 353 & 385 & 247 & 328 \\
$\mathrm{Cu}$ & 1730 & 1708 & 1759 & 1800 & 444 & 684 & 1036 & 2041 & 1795 & 1030 & 1622 \\
$\mathrm{Zn}$ & 3642 & 3466 & 3533 & 3223 & 1154 & 1599 & 2963 & 2407 & 3716 & 1919 & 2681 \\
$\mathrm{Ga}$ & 464 & 449 & 466 & 404 & 0 & 152 & 295 & 445 & 347 & 179 & 324 \\
$\mathrm{As}$ & 377 & 403 & 418 & 396 & 0 & 150 & 231 & 350 & 281 & 124 & 252 \\
$\mathrm{Rb}$ & 4682 & 4596 & 4959 & 4528 & 1314 & 2063 & 3251 & 3960 & 3360 & 2009 & 3110 \\
$\mathrm{Sr}$ & 4704 & 4726 & 5493 & 4795 & 1803 & 2733 & 4350 & 4560 & 4643 & 2962 & 4055 \\
$\mathrm{Y}$ & 2145 & 1872 & 2048 & 1931 & 591 & 917 & 1090 & 2125 & 1368 & 928 & 1474 \\
$\mathrm{Zr}$ & 23622 & 22411 & 25118 & 21814 & 5079 & 8452 & 14639 & 17558 & 16390 & 9756 & 14568 \\
\hline
\end{tabular}

Tabela 6. Áreas líquidas dos elementos encontrados em cada medida da amostra "SCXI 766".

Fonte: Elaborada pelos autores, 2016.

2 É preciso ter em mente que o feixe de raios X do sistema portátil utilizado irradia uma área um pouco maior do que a largura das faixas da pintura na face externa. Portanto, pode haver informações do vermelho misturadas nas medidas de branco e vice-versa nos pontos dessas regiões de faixas. 


\begin{tabular}{cccccccc}
\hline Elemento & Razão B1 & Razão B2 & Razão B3 & Razão B4 & Razão A1 & Razão A2 & Razão A3 \\
\hline $\mathrm{K}$ & 1,34 & 1,22 & 1,20 & 1,20 & 0,54 & 0,62 & 1,02 \\
$\mathrm{Ca}$ & 1,09 & 1,23 & 1,74 & 1,13 & 0,33 & 0,58 & 1,08 \\
$\mathrm{Ti}$ & 0,87 & 0,76 & 0,83 & 0,92 & 0,36 & 0,56 & 1,01 \\
$\mathrm{Cr}$ & 1,03 & 0,99 & 1,33 & 1,10 & 0,43 & 0,54 & 1,07 \\
$\mathrm{Mn}$ & 0,48 & 0,43 & 0,38 & 0,45 & 0,94 & 0,98 & 2,40 \\
$\mathrm{Fe}$ & 0,98 & 0,99 & 1,14 & 1,00 & 0,34 & 0,50 & 0,88 \\
$\mathrm{Ni}$ & 0,83 & 0,90 & 0,94 & 1,20 & 0,48 & 0,50 & 0,71 \\
$\mathrm{Cu}$ & 1,07 & 1,05 & 1,08 & 1,11 & 0,27 & 0,42 & 0,64 \\
$\mathrm{Zn}$ & 1,36 & 1,29 & 1,32 & 1,20 & 0,43 & 0,60 & 1,11 \\
$\mathrm{Ga}$ & 1,43 & 1,39 & 1,44 & 1,25 & 0,00 & 0,47 & 0,91 \\
$\mathrm{As}$ & 1,50 & 1,60 & 1,66 & 1,57 & 0,00 & 0,60 & 0,92 \\
$\mathrm{Rb}$ & 1,51 & 1,48 & 1,60 & 1,46 & 0,42 & 0,66 & 1,05 \\
$\mathrm{Sr}$ & 1,16 & 1,17 & 1,36 & 1,18 & 0,44 & 0,67 & 1,07 \\
$\mathrm{Y}$ & 1,46 & 1,27 & 1,39 & 1,31 & 0,40 & 0,62 & 0,74 \\
$\mathrm{Zr}$ & 1,62 & 1,54 & 1,72 & 1,50 & 0,35 & 0,58 & 1,01 \\
\hline $\mathrm{T}$ & & &
\end{tabular}

Tabela 7. Razões entre as áreas líquidas da região com decoração e a média cerâmica da amostra "SCXI 766". Fonte: Elaborada pelos autores, 2016.

A Fig. 7 apresenta a comparação entre os espectros de fluorescência medidos para a pasta cerâmica, uma região branca e uma vermelha. Podemos observar as diferenças entre as áreas dos picos de Fe, maior no pigmento vermelho do que no branco e na pasta cerâmica, assim percebe-se em ambos os pigmentos maiores quantidades de $\mathrm{Rb}, \mathrm{Y}, \mathrm{Sr}$ e Zr em relação à pasta.

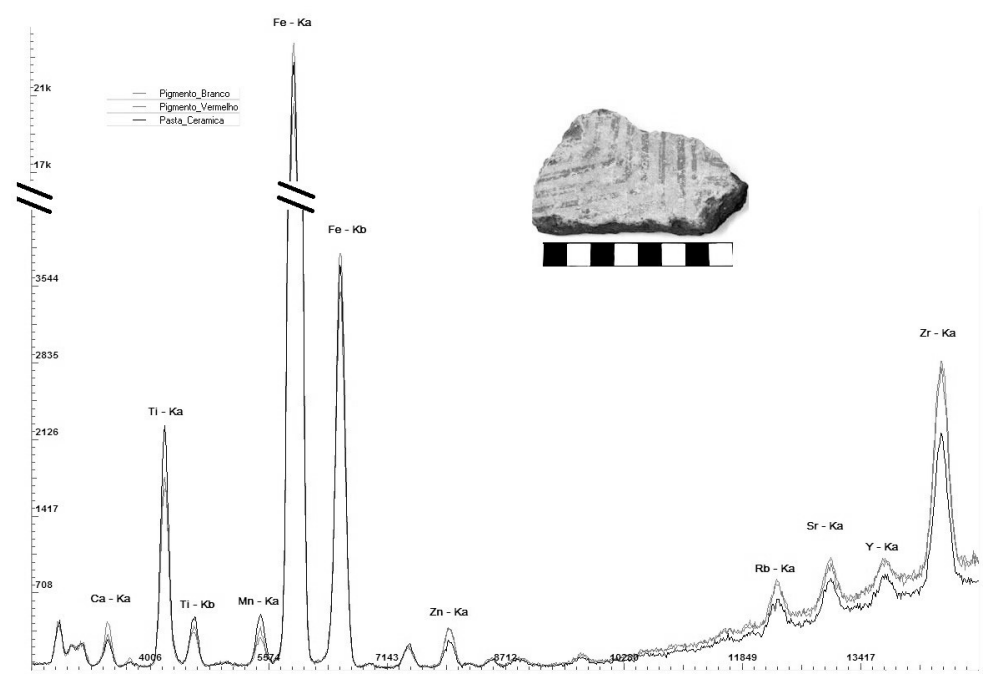

Fig. 7. Fragmento "SCXI 766", comparação entre espectros de fluorescência de raios X de uma das medidas da pasta cerâmica e dos engobos branco e vermelho. Escalas: Contagens versus energia dos raios X (em KeV). Fonte: Elaborada pelos autores, 2016. 
Materiais pictóricos da cerâmica Guarani do alto Uruguai a partir de medidas de fluorescência de raios X R. Museu Arq. Etn., 28: 133-144, 2017.

A pintura da amostra "SCXI 766" apresenta concentrações de K (potássio), Ca (cálcio), Zn (zinco), Ga (gálio), As (arsênio), Rb (rubídio), Sr (estrôncio), Y (ítrio) e Zr (zircônio) maiores que a média da pasta cerâmica. Nas medidas sobre o vermelho, pode-se observar que há aumento de $\mathrm{Fe}$, apesar de a razão ser próxima de 1 . Como o Fe é elemento principal das cerâmicas, uma variação pequena na razão é suficiente para diferir muito na área total líquida. Além disso, o Fe tem razões maiores apenas nos pontos sobre o vermelho e no restante é sempre menor (muito menor em alguns casos). O pigmento vermelho utilizado tem como elemento chave o $\mathrm{Fe}$ (ferro), o que indica uso de argilas ricas desse elemento, ou seja, em óxidos.

As medidas realizadas sobre o branco mostram aumento de $\mathrm{K}, \mathrm{Cu}, \mathrm{Zn}, \mathrm{Ga}, \mathrm{As}, \mathrm{Rb}$, $\mathrm{Sr}$, Y e Zr. Desses elementos, o Zn é responsável pela coloração branca em pigmentos modernos. Porém, como o branco de zinco é um composto artificial criado no século XIX, não há evidências de que em suas formas naturais ele seja o responsável pela coloração branca. $\mathrm{O}$ que pode ser afirmado é que a matéria-prima usada para tal cor, empregada nos tratamentos superficiais dessas cerâmicas, apresentava maiores quantidades de $\mathrm{K}, \mathrm{Zn}, \mathrm{Rb}, \mathrm{Y}$ e $\mathrm{Zr}$.

As medidas de $\mathrm{A} 1$ e $\mathrm{A} 2$, referentes à face interna, ficaram muito abaixo da média da pasta cerâmica, provavelmente em virtude da maior camada de ar que fica entre a amostra e o detector, o que se deve à geometria do fragmento. O elemento principal nas medidas internas é o manganês $(\mathrm{Mn})$, que possui razão muito maior que os demais elementos. Na parte interna do fragmento foi utilizada uma pasta que também tem como elemento-chave de sua coloração o $\mathrm{Mn}$, indicando a presença de materiais ricos em óxidos desse elemento, além do Fe.

Ainda sobre o percentual de zinco, ele não é maior somente na amostra "SCXI 766". As amostras "SCXIII 54" e "SCXIII 781" também apresentam alto percentual desse elemento nas medidas dos pigmentos. Pode-se dizer que a quantidade variou conforme a espessura do engobo, e que o material utilizado na superfície apresenta mais zinco em sua composição do que na pasta cerâmica.

\section{Considerações finais}

Muito embora ainda sejam necessárias novas análises arqueométricas para detalhar melhor a base dos materiais pictóricos utilizados na cerâmica da unidade Guarani do Alto rio Uruguai, os trabalhos já realizados trazem dados interessantes a esse respeito. A pesquisa de Ali et al. (2017) permitiu identificar através da análise de MEB-EDX que, a eleição de matérias primas empregadas para formar as mesclas de pigmentos, demonstram diferentes esferas de circulação da informação dentro da mesma unidade cultural e a utilização principalmente de pigmentos com origem inorgânica. Neste trabalho aplicamos outro método arqueométrico e por meio das medidas de fluorescência de raios $\mathrm{X}$ pode-se concluir que os pigmentos vermelho e branco provêm de materiais inorgânicos derivados de minerais terrosos, muito possivelmente encontrados no entorno das áreas de assentamento.

No Alto Rio Uruguai existem centenas de sítios Guarani do final do Holoceno, alguns apresentam cerâmicas com pintura bem preservada que possibilitariam novos dados, a fim de comparar e ampliar os resultados aqui apresentados. As três amostras analisadas integraram um estudo mais amplo sobre tecnologia cerâmica, no qual foram aplicados diferentes métodos arqueométricos (Carbonera 2014).

Para além das análises com materiais cerâmicos de diferentes sítios da região, poderiam ser desenvolvidos estudos com as matérias-primas locais, visando entender a origem dos pigmentos - com isso, seria possível comparar diferenças interssítios e ampliar o conhecimento sobre os aspectos tecnológicos dos ceramistas Guarani.

\section{Agradecimentos}

Dra. Sonia Hatsue Tatumi, da Universidade Federal de São Paulo (Unifesp - Campus Baixada Santista) pelas análises de TL. Regiane Eberts pelo tratamento das imagens fotográficas. 
CARBONERA, M.; APPOLONI, C.R.; SANTOS, G.H. Guarani ceramics pictorial material from X-ray fluorescence measurements. R. Museu Arq. Etn., 28: 133-144, 2017.

Abstract: The precolonial Guarani used to be spread over large areas in South America, especially in regions of the Prata River basin and Brazil's coastal areas. Their great feature in terms of material culture is their ceramic production, especially for containers painted inside and outside. From X-ray fluorescence measurements, we present here a data analysis from pigments used in the production of paints applied in Guarani ceramic finishing of three archaeological sites located in Volta do Uvá, Upper Uruguay River. This analysis showed that red and white pigments come from inorganic materials, derived from earth minerals.

Keywords: Guarani Unit; Ceramics; X-ray fluorescence; Upper Uruguay River.

\section{Referências bibliográficas}

Ali, S.; Pérez, M.; Carbonera, M.; Bozzano, P.; Domínguez, S. 2017. Pigmentos de la alfarería Tupiguarani: análisis físico-químico MEB-EDX. Pesquisas, Antropologia 73: 31-51.

Appoloni, C.R.; Parreira, P.S.; Souza, E.; Quacchia, J.C.A.; Nascimento Filho, V.F.; Gigante, G.E.; Cesareo, R.; Cunha e Silva, R.M. 1997. Estudo de cerâmicas arqueológicas do Paraná por técnicas nucleares não destrutivas. Revista do Museu de Arqueologia e Etnologia, Suplemento 2: 135-149.

Appoloni, C.R. 2015. Estudos de cerâmicas arqueológicas brasileiras por metodologias nuclear-atômico-moleculares não destrutivas. Cadernos do CEOM 28: 21-29.

Caldarelli, S.B. (Org.). 2010. Arqueologia preventiva na UHE Foz do Chapecó, SC/RS. Relatório Final. Unpublished report. Scientia Consultoria Científica, Florianópolis.

Carbonera, M. 2014. A ocupação pré-colonial do alto Rio Uruguai, SC: contatos culturais na Volta do Uvá. Tese de Doutorado. Universidade de São Paulo, São Paulo.

De Masi, M.A.N. 2012. Relatório Projeto de Salvamento Arqueológico UHE Foz do Chapecó (Reservatório). Florianópolis.
Goulart, M. (Coord.). 1987. A pré-história da volta do Uvá-SC/RS: Barragem Itá. UFSC/Eletrosul, Florianópolis.

Goulart, M. (Coord.). 1988. Situação atual das pesquisas arqueológicas: Barragem de Itá-SC/RS. UFSC/Eletrosul, Florianópolis.

Goulart, M. (Coord.). 1995. Cadastro dos Sítios Arqueológicos. Volume I, Tomos: I, II e III. Eletrosul, Florianópolis.

Goulart, M. (Coord.). 1997. Projeto Salvamento Arqueológico do Uruguai. Univali, Itajaí.

Kern, D.C., et al. 2013. Pesquisas arqueométricas na Amazônia, com ênfase no material cerâmico. In: Rubin, J.C.R.; Silva, R.T. (Orgs.). Geoarqueologia. Ed. da PUC Goiás, Goiânia, 45-68.

Mohr, M. 2015. Cerâmica Guarani policrômica: um estudo de caso a partir da coleção Caxambu do Sul. Trabalho de Conclusão de Curso. Universidade Federal da Fronteira Sul, Chapecó.

Oliveira, K. 2009. A cerâmica pintada da tradição Tupiguarani: estudando a coleção Itapiranga, SC. Arqueologia do Rio Grande do Sul, Brasil. Documentos 11: 5-88. 
Materiais pictóricos da cerâmica Guarani do alto Uruguai a partir de medidas de fluorescência de raios X

R. Museu Arq. Etn., 28: 133-144, 2017.

Oliveira, K. 2011. Um caso de "regionalismos culturais" por meio do estudo da cerâmica pintada Tupiguarani de Itapiranga (SC). In: Carbonera, M.; Schmitz, P.I. (Orgs.). Antes do Oeste Catarinense: arqueologia dos povos indígenas. Editora Argos, Chapecó, 219-240.

Piazza, W. 1969. Notícia Arqueológica do Vale do Uruguai. Publicações avulsas do Museu Paraense Emílio Goeldi 10: 55-70.

Piazza, W. 1971. Dados Complementares à Arqueologia do Vale do Rio Uruguai. Publicações avulsas do Museu Paraense Emílio Goeldi 15: 71-86.

Rye, O. 1981. Pottery Technology: principles and reconstruction. Taraxacum, Washington. $150 \mathrm{p}$.
Rohr, J.A. 1966. Pesquisas arqueológicas em Santa Catarina, os sítios arqueológicos do município de Itapiranga. Pesquisas 15: 21-60.

Schmitz, P.I. 1957. Um paradeiro Guarani no Alto Uruguai. Pesquisas 1: 122-142.

Shepard, A.O. 1956. Ceramics for the archaeologist. Carnegie Institution of Washington, Washington, DC.

Souza, L.A.C.; Jácome, C.P.; Rocha, S.O.G. 2010. Materiais pictóricos em cerâmicas Tupiguarani de Minas Gerais. In: Prous, A.; Lima, T.A. Os Ceramistas Tupiguarani. Superintendência do IPHAN em Minas Gerais, Belo Horizonte, 1: 223-242. 